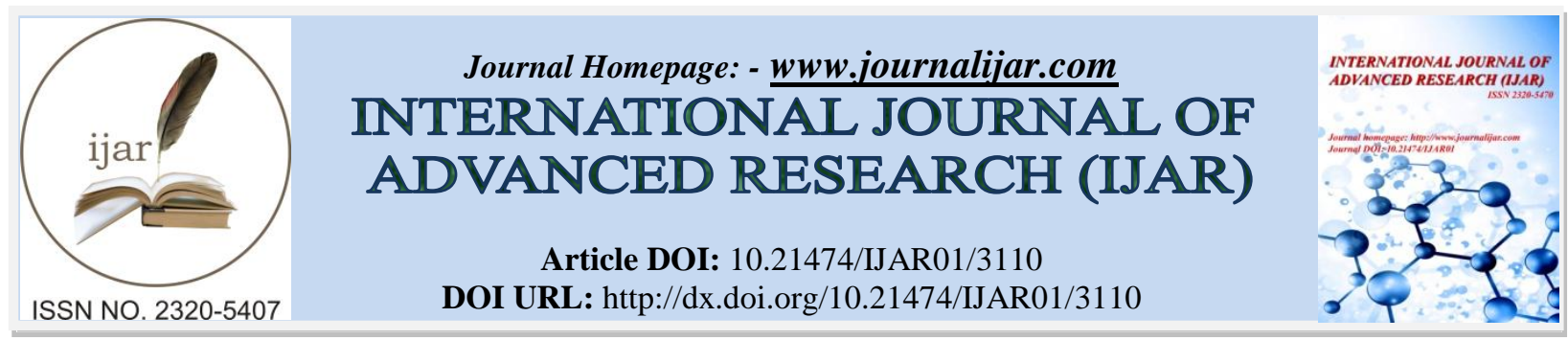

RESEARCH ARTICLE

\title{
EXPERMENTAL AND THEORETICAL STUDY OF GOLD ADSORPTION ONTO POLYMERIC SORBENT.
}

"Odonchimeg. S. ${ }^{1}{ }^{*}$ Javkhlantugs. N. $^{2}$, Tegshjargal. Kh. ${ }^{2}$, and Oyun. J. ${ }^{3}$.

1. Central Laboratory of Chemistry, Erdenet Mining Corporation, Orkhon 22100, Mongolia.

2. School of Engineering and Applied Sciences, National University of Mongolia, Ulaanbaatar 14201, Mongolia.

3. Department of Chemistry, Ulaanbaatar University, Ulaanbaatar 13374, Mongolia.

\section{Manuscript Info}

\section{Manuscript History}

Received: 07 December 2016

Final Accepted: 02 January 2017

Published: February 2017

\section{Key words:-}

low-content gold, copper ore, copper concentrate, waste copper, PSTDTpolymer.

\section{Abstract}

Polystyrene-azo-thiazandithion-2,4 (PSTDT) polymer was used to increase the gold content for analysis of waste copper, copper ore and concentrate. The optimum conditions of the sorption capacity of sorbent, $\left[\mathrm{H}^{+}\right]$, temperature and time dependence enrichment of gold content were examined to increase analysis efficiency by using treatment of PSTDT polymer. The moleculer structure of PSTDT polymer with gold were successfully determined using by FT-IR and theoretical calculations.

Copy Right, IJAR, 2017,. All rights reserved.

\section{Introduction:-}

The atomic absorption spectroscopy (AAS) method is usefully for determination of low-content precious elements in biological (Olmedo et all.,2013), and geological samples (Hoffman., et all 1998). One of the precious metals is gold. Comparison of different gold recovery methods as amalgamatoin, cyanidation was investigated previously (Hylander et all., 2007). Hoffman et al. (Hoffman., et all 1998), describedthe gold analysis in geological samples by fire-assaying methods which includes instrumental neutron activation, AAS, graphit furnace-atomic absorption or inductively coupled plasma emission mass spectroscopy. The functional polymers can been used for determination of low-concentration gold in ores and minerals by using AAS such as silicon organic adsorbent PSTM-3T (Pozhidaev et all., 2013). The PSTM-3T polymer also had been investigated for removal of copper and chromium ions from aqueous solution (Narantsogt et all., 2014). PSTM-3T polymer includes thiocarbamide functional group which forms the metal complexes.

The Erdenet Mining Corporation (EMC) is one of the largest copper and molybdenum mining and processing factories in the world that located on the northern of Mongolia. The copper is concentrated by using flotation method of sulfide minerals. The concentration of gold in waste copper, copper ore and copper concentrate has been determined by using the AAS in Central Laboratory of Chemistry of EMC which method is not efficiency. The enrichment of precious metals is very useful for recovery and analytical chemistry. Monitoring the gold concentration in waste copper, copper ore and concentrate is important for mining. In recent, the polymer compound is treated into ores to increase the concentration of plate and precious metals. One of the polymer is the polystyrene-azo-thiazondithion-2,4 (PSTDT) which firstly synthesized by Basargin et al (Basargin et all., 1995). The PSTDT polymer can been selectively determine the low-content gold samples by using enrichment method. In this present work, we determined the gold content in waste copper, copper ore and concentrate of EMC.

Corresponding Author:- Javkhlantugs. N, Odonchimeg. S.

Address:- School of Engineering and Applied Sciences, National University of Mongolia, Ulaanbaatar 14201, Mongolia.

Central Laboratory of Chemistry, Erdenet Mining Corporation, Orkhon 22100, Mongolia. 


\section{Materials and Methods:-}

Materials:-

Poly-styrene-azo-thiazandithion-2,4 (PSTDT) polymer (Astralabor, Russia) was used to determine the gold content in waste copper, copper ore and concentrate. The PSTDT polymer (Fig. 1a) is not dissolve in water, acid, base and organic solvents that includes nitrogen and sulfur atoms at ortho-position which forms a stable chelate complex with gold. Gold atom substitutes a hydrogen atom of imine group and connects with sulfur atom by coordination bond(Fig. 1b) (Pozhidaev et all., 2013). Standard solution and certified reference sample were used $1 \mathrm{mg} / \mathrm{ml}$ gold solution (ACROS Organics) and $0.211 \mathrm{ppm}$ gold contend (OREAS 13b), respectively.

\section{Optinum condition gold adsorption}

In order to define the optimum condition as temperature $\left(20^{\circ} \mathrm{C}, 50{ }^{\circ} \mathrm{C}\right.$ and $\left.100{ }^{\circ} \mathrm{C}\right)$, time $(5-30$ minutes $)$ and $\mathrm{HCI}$ $(0.5,1.0,1.5 \mathrm{~N}), \mathrm{HNO}_{3}(0.5,1.0,1.5 \mathrm{~N})$ affecting to the gold adsorption, $25 \mathrm{mg}$ PSTDT with $500 \mathrm{ppb}$ gold standard solution were taken for $100 \mathrm{ml}$ solution and stirred on the magnetic mixer. Gold contents in the solution were measured by spectrophotometry (MAPADA V-1600PC) to form the color complex with rodasol-XC. Adsorption efficiency of the gold was calculated as following equation:

$$
R=\frac{q_{a}-q_{f}}{q_{a}} \times 100 \%
$$

Where, $R, q_{a}$, and $q_{f}$ are the adsorption efficiency (\%), concentrations (ppb) of the gold in the standard solution and filtrate solution, respectively.

A. Sorption capacity of sorbent

The solutions of gold with concentrations of $5,10,15,20,25,30,35,40,45,50$ and 55 ppb were prepared from the standard solution to determine the maximum amount of gold per adsorbent. $50 \mathrm{mg}$ PSTDT added into each solutions at optimum condition then filtrate solutions were analyzed to adsorption efficiency. Sorption capacity of sorbent is calculated following equation:

$$
S C S_{A u}=\frac{\left(C_{0}-C\right) * V}{m}
$$

Where, $\mathrm{C}_{0}, \mathrm{C}$-gold concentration in initial and remained solution, respectively, $\mathrm{V}-50 \mathrm{ml}$ standard solution, $\mathrm{m}-50$ mg sorbent
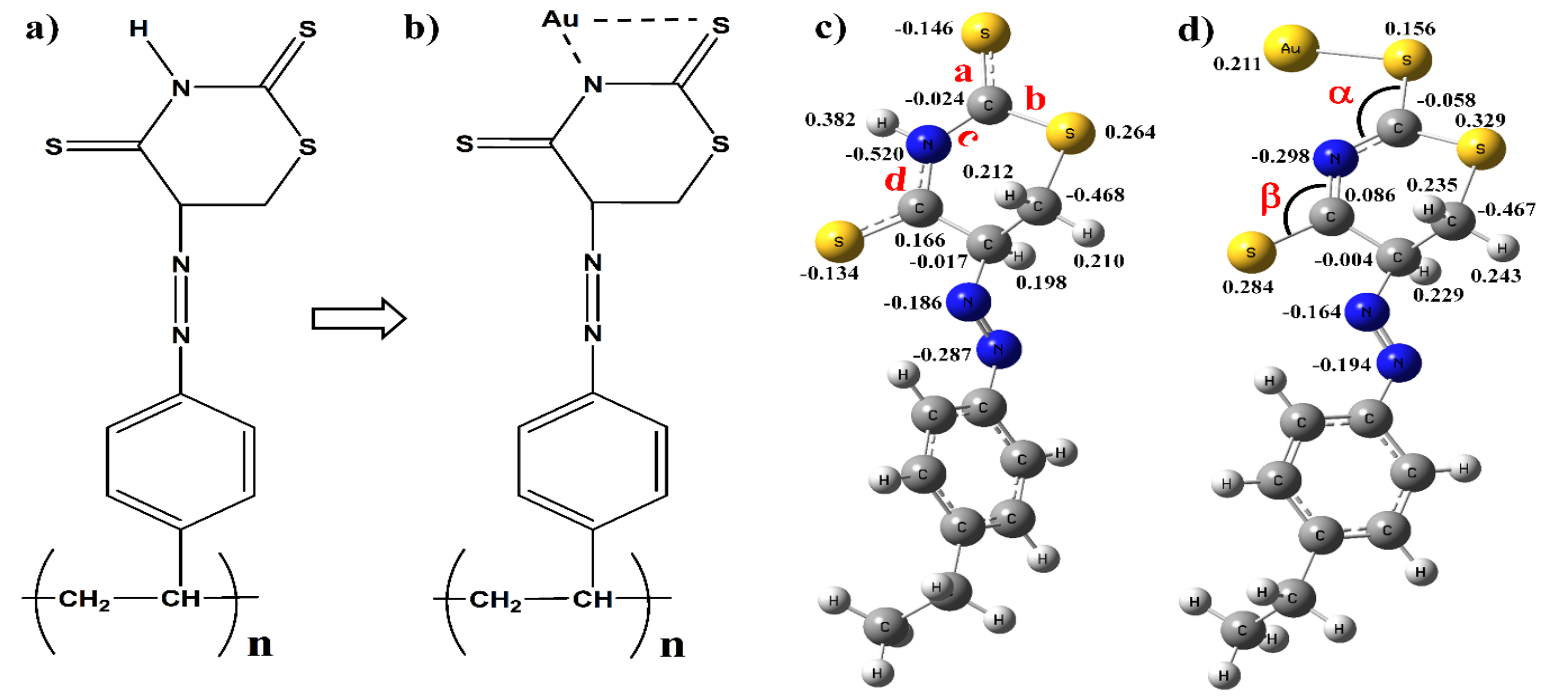

Fig. 1: Representation of molecular structure of PSTDT polymer (a) and PSTDT-Au (b). The optimized structures of PSTDT(c) and PSTDT-Au (d) with Mulliken atomic charges for selected atoms. Sulfur, nitrogen, carbon, hydrogen, and gold atoms are shown by yellow, blue, dark grey, light grey and yellow, respectively. 


\section{Determination of gold content in samples:-}

Experimental procedures were applied to gold determination can be broadly divided into three stages as the sample decomposition, enrichment and analysis stages which were summarized as a scheme in Figure 2

Sample decomposition stage Samples were calcinated at $650{ }^{\circ} \mathrm{C}$ then were dissolved in nitric acid and were evaporated the solution. The powder had been calcinated at $450{ }^{\circ} \mathrm{C}$ to form the copper oxide. The formed oxide was dissolved in solution of $\mathrm{H}_{2} \mathrm{SO}_{4}: \mathrm{H}_{2} \mathrm{O}_{2}(3 \%)$ with ratio $1: 10$. The excess solution of hydrogen peroxide was added and boiled the solution then was added $\mathrm{NaCl}$ and $\mathrm{KI}$ with concentration of $10 \%$ to separate the gold, platinum, silver and palladium. This procedure was repeated twice. The precipitate was filtered and calcinated at $600{ }^{\circ} \mathrm{C}$. The precipitate was dissolved in "Aqua regia" solution and evaporated then dissolved in $1 \mathrm{~N}$ hydrochloric acid. (A solution).

Enrichment stage $50 \mathrm{mg}$ sorbent( PSTDT) were added into "solution A" to enrich the gold in the optimum condition by mixing. After the formation of chelate complex, the solids were filtered and were calcined at $550{ }^{\circ} \mathrm{C}$ then dissolved in $100 \mathrm{ml}$ hydrochloric acid (1 N) then filtrate.

Analysis stage The sample burned by air-acetylene flam at $2125-2400{ }^{\circ} \mathrm{C}$ and measured the gold content at 242.7 $\mathrm{nm}$ wavelength using flame atomic absorption spectroscopy (FAAS) (Perkin Elmer AAnalyst 800).

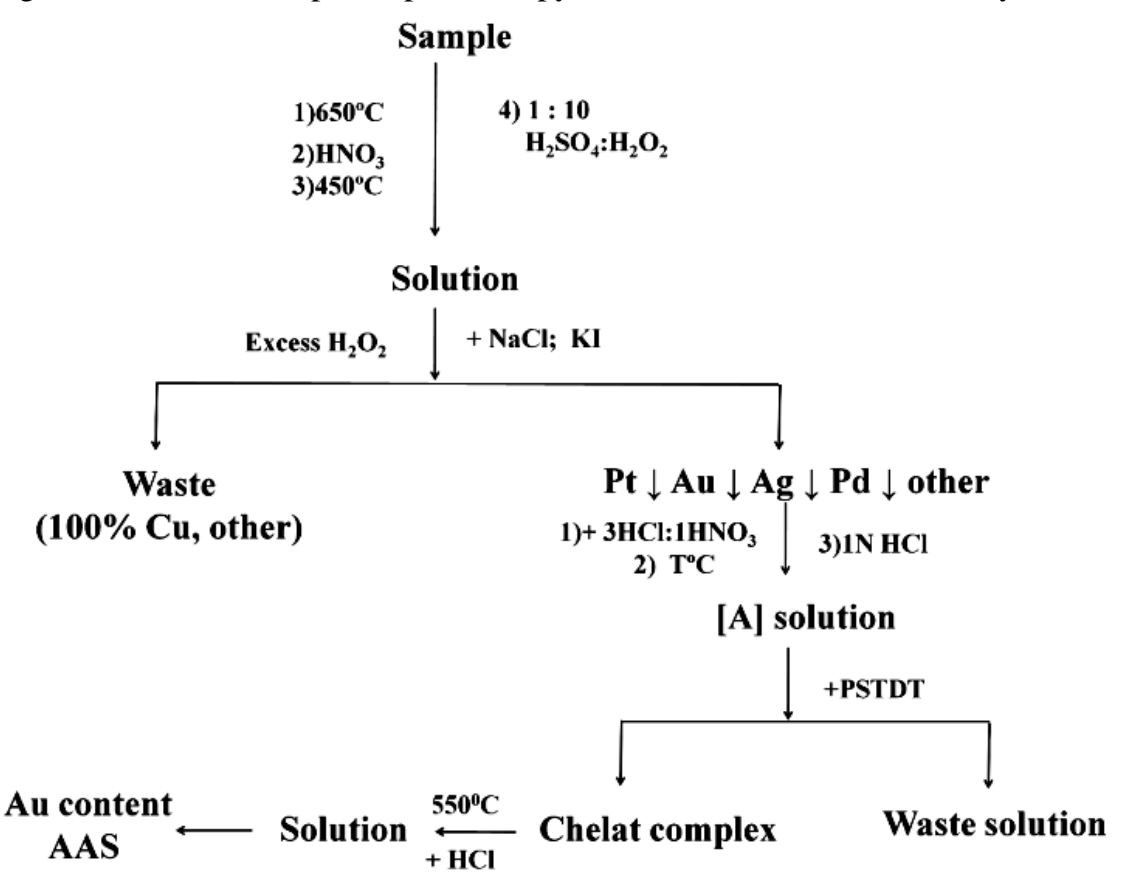

Fig. 2:- Scheme of experimental procedures for determination of gold content.

\section{Fronter-Transform Infrared (FT-IR) spectroscopy:-}

The chemical bond frequencies of functional groups of polymer before and after treatment of sample were analyzed by using Frontier-Transform Infrared (FT-IR) spectrophotometer (IRPrestige-21, Shimadzu, Tokyo, Japan). The powdered samples were mixed with $\mathrm{KBr}$ and made the pellets. The FT-IR spectra were obtained with frequency range of $4000-400 \mathrm{~cm}^{-1}$.

\section{Computational method:-}

The optimization and frequency calculations of PSTDTand PSTDT-Au (Fig. 1c and d) complex were carried out using density functional theory (DFT) with Becke three parameter method (Becke .,1993), (Becke., 1988)and (Lee Yang Parr et all., 1988), correlation exchange with 6-31G(d) (Hehre et all., 1987) and LanL2DZ basis sets by Gaussian09 program. (Barone et all., 2009) 6-31G(d) basis set was applied for H, C, N, and S atoms, and LanL2DZ was applied for Au cation. Spin multiplicity of PSTDT and PSTDT-Au complex was singlet and doublet, respectively. All the convergent precisions were the system default values, and the all calculations were carried out 
on the standard lab-level workstations with AMD Opteron 285 dual core CPU. Data visualization was carried out using Gauss View 03 (Frish et all., 2007).

\section{Result and Discussion:-}

Firstly, the adsorption optimum conditions of the sorption capacity of sorbent, $\left[\mathrm{H}^{+}\right]$, temperature and time dependence of PSTDT polymer for gold adsorption were established as $<45 \mathrm{mg} / \mathrm{g}, 1 \mathrm{~N}, 20{ }^{\circ} \mathrm{C}$ and $15 \mathrm{~min}$, respectively (Fig. 3 and Fig. 4).

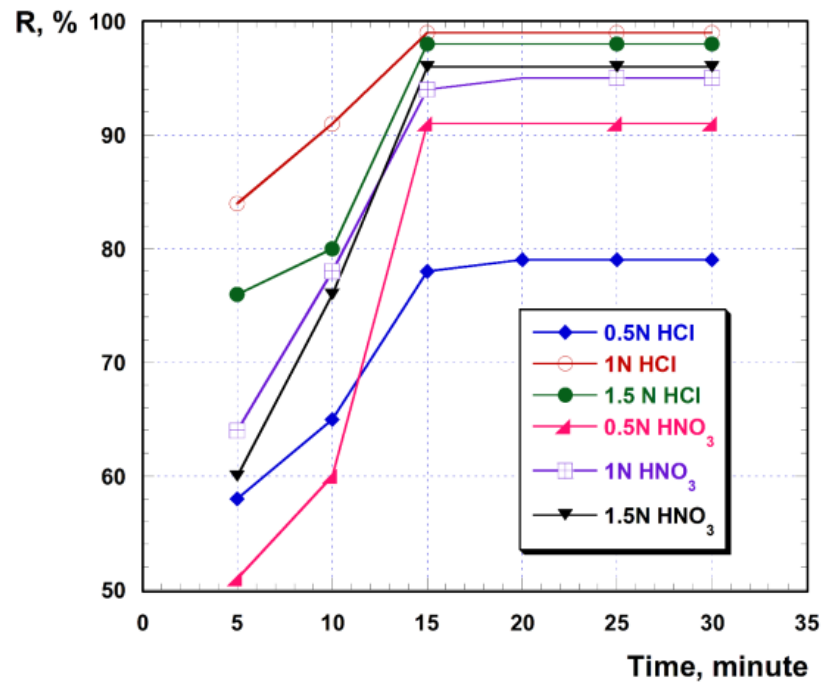

Fig. 3:- Time dependence of adsorption efficiencyfor the different acids.

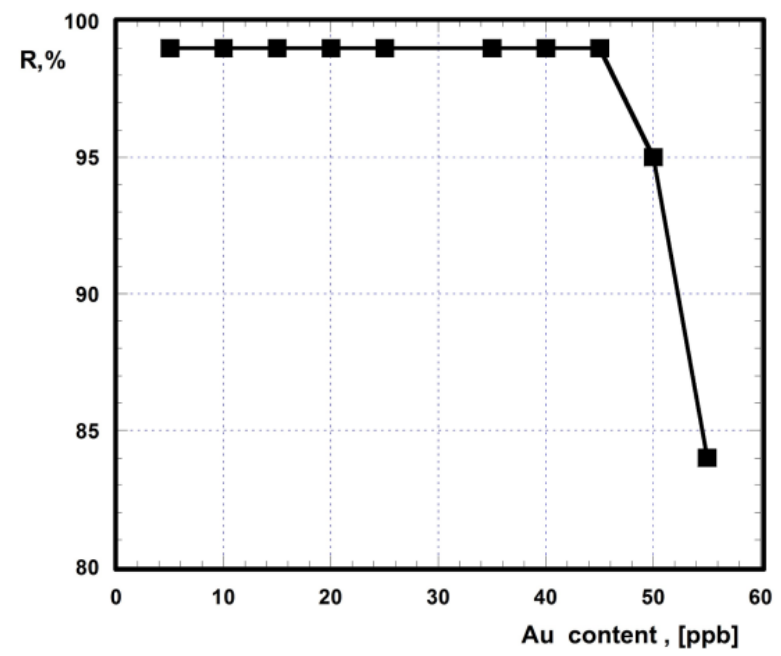

Fig. 4:- Adsorption efficiency of PSTDT polymer depends on the gold concentration.

Table 1 shows that the determined gold contents in copper ore, copper concentrate and waste copper by using our chemical treated (CT) flame atomic absorption spectroscopy (FAAS) to compare with assay analysis (AA) FAAS and inductively coupled plasma (ICP) mass spectrometry (MS) methods. The gold contents in copper concentrate and waste copper by using CT-FAAS were higher than by using ICP-MS method which mean that the low-content gold determination is enriched by the PSTDT polymer are higher efficiency in analysis of copper industry.

Table 1:- The Comparison of Gold Content by Using Different Methods of Chemical Treatment (CT), Assay Analysis (AA) Flame Atomic Absorption Spectroscopy (FAAS) and Inductively Coupled Plasma (ICP) Mass Spectrometry (MS). 


\begin{tabular}{|l|l|l|l|}
\hline \multirow{2}{*}{ Samples } & \multicolumn{3}{|l|}{ Gold content, ppm } \\
\cline { 2 - 4 } & CT-FAAS & AA-FAAS & ICP-MS \\
\hline Copper ore & 0.004 & NA & 0.005 \\
\hline Copper concentrate & 0.048 & 0.040 & 0.044 \\
\hline Waste copper & 0.005 & NA & 0.002 \\
\hline OREAS 13b $(0.211 \mathrm{ppm})$ & 0.214 & 0.210 & 0.213 \\
\hline
\end{tabular}

The functional groups of PSTDT polymer before and after treatment of gold samples were identified using FT-IR experiment and the spectrum is shown in Fig. 5.

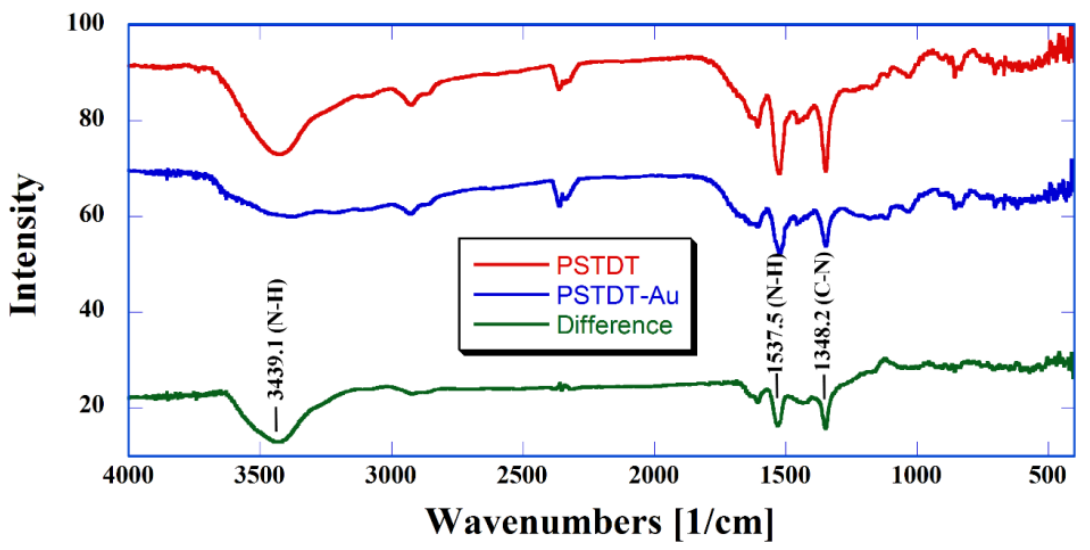

Fig. 5:- FT-IR spectra of PSTDT polymer before (red) and after (blue) treatment of gold sample and their difference (green).

In Fig. 5, the observable IR signals for PSTDT polymer were 1521.8 and $3375.4 \mathrm{~cm}^{-1}$ for $\mathrm{N}-\mathrm{H}, 1348.2 \mathrm{~cm}^{-1}$ for C-N (Table 2).

Table 2:- The Comparison of Theoretical and Experimental Frequencies of PSTDT and PSTDT-Au. The Percentage of Relative Deviation of Model in Different Frequencies is Shown In Parenthesis.

\begin{tabular}{|l|l|l|l|l|l|l|}
\hline \multirow{2}{*}{ Groups } & \multicolumn{6}{l}{ Wavenumbers, [1/cm] } \\
\cline { 2 - 7 } & PSTDT & Exp. & $\Delta[\%]$ & PSTDT-Au & Exp. & $\Delta[\%]$ \\
\hline \multirow{2}{*}{ N-H } & 3518.5 & 3375.4 & -4.0 & - & - & - \\
& 1514.6 & 1521.8 & 0.5 & - & 1525.7 & -0.3 \\
\hline \multirow{2}{*}{ C-N } & 1367.9 & 1348.2 & -1.5 & 1487.7 & 1348.2 & -10.3 \\
\cline { 2 - 7 } & 1292.8 & - & - & 1268.6 & 1348.2 & 5.9 \\
\hline
\end{tabular}

The intensities at these wavenumbers were decreased after the treatment of PSTDT to copper samples. The differences of the intensities of $-\mathrm{NH}$ group are shown in the figure which means that the gold was adsorbed onto PSTDT polymer. The -CS group shows the important for the sorption of the metal (Narantsogt et all., 2014) therefore the vibration intensity of C-N bond was decreased in Fig. 5. The IR signals were similar with the group frequencies (Coates ., 2004) vice versa the frequencies do not shown for PSTDT polymer after treatmentsof the gold sample. It shows that the gold atom substituted the hydrogen atom of imine group and connected with sulfur atom by coordination (Fig. 1b) Pozhidaev et all., 2013). The theoretical calculations were carried out by B3LYP method with 6-31G(d) basis set and optimized PSTDT polymer and PSTDT-Au structures are shown in Fig. 1c and d with Mulliken atomic charges for selected atoms. After the Au adsorption " $a$ " bond length, " $\alpha$ " and " $\beta$ " bond angles were increased (Fig. 1c and d). Au-S and Au-N bond lengthsare $2.338 \AA$ and $3.089 \AA$, respectively, which are similar results with previous report. In this study, the frequency calculations of optimized structures of PSTDT polymer and PSTDT-Au (Fig. 1c and d) were investigated using the B3LYP method with 6-31G(d) basis set to compare the experimental IR results.. In theoretical calculations, the values for $\mathrm{N}-\mathrm{H}$ bond frequencies have relative deviation less than $4 \%$ and the deviations of values for $\mathrm{C}-\mathrm{N}$ bond frequency are $1.5 \%$ (Table 2). Calculated frequencies of $\mathrm{CN}$ bond in PSTDT-Au were $1487.7 \mathrm{~cm}^{-1}$ and $1268.6 \mathrm{~cm}^{-1}$ and deviated by $10.3 \%$ and $5.9 \%$ from experimental value of PSTDT polymer. The experimental IR spectrum of PSTDT-Au system had shifted intensities of CN bond vibration. The theoretical frequency result of NH bond disappeared on IR spectrum of PSTDT-Au structure and $\mathrm{N}=\mathrm{N}$ bond intensity was increased from IR spectrum of PSTDT (Fig. 6). 

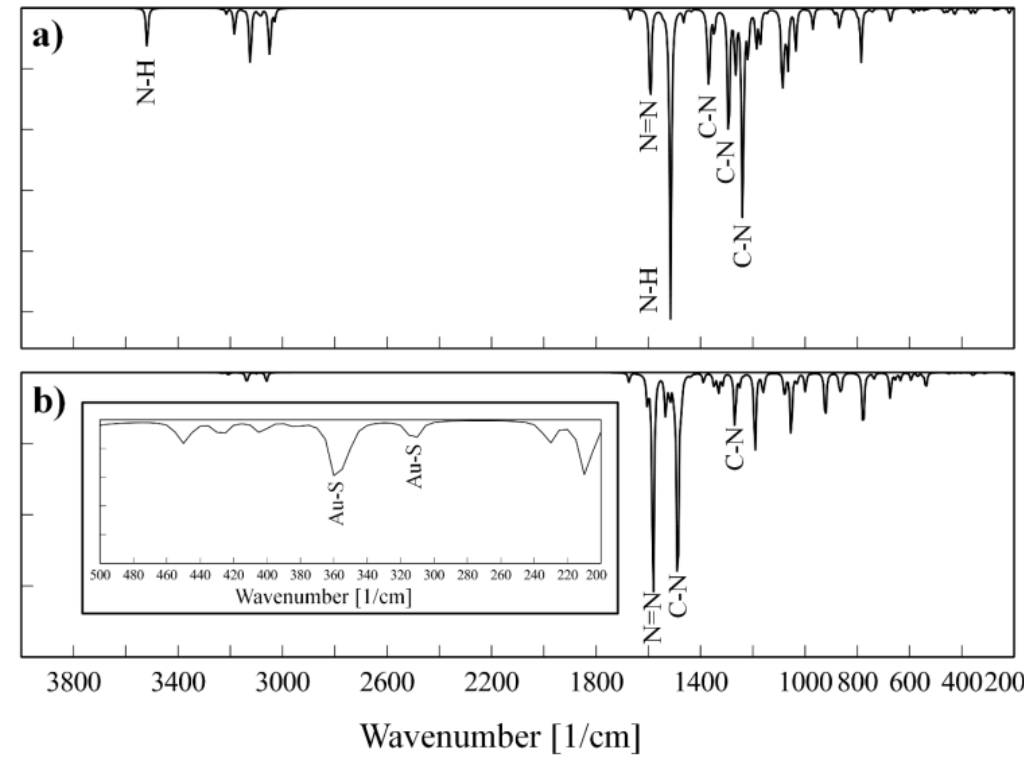

Fig. 6:- Calculated IR spectra of PSTDT (a) and PSTDT-Au (b). IR spectrum of PSTDT-Au between $200 \mathrm{~cm}^{-1}$ and $500 \mathrm{~cm}^{-1}$ (b, inset).

The calculated frequencies of Au-S were $314.3 \mathrm{~cm}^{-1}$ and $356.8 \mathrm{~cm}^{-1}$ (Fig. 6b). N=N bond characteristic was dramatically changed and indicated in HOMO orbitals (Fig. 7a and c). LUMO orbitals are shown in Fig. 7b and d where Au-S bond had partial occupation of LUMO orbital. The theoretical frequency values are in good agreement with experimental values, the same as previous reports (Narantsogt et all., 2014), (Pousti et all., 2013). Finally, the PSTDT polymer is a good enrichment of gold content to use the analysis of gold in copper samples.
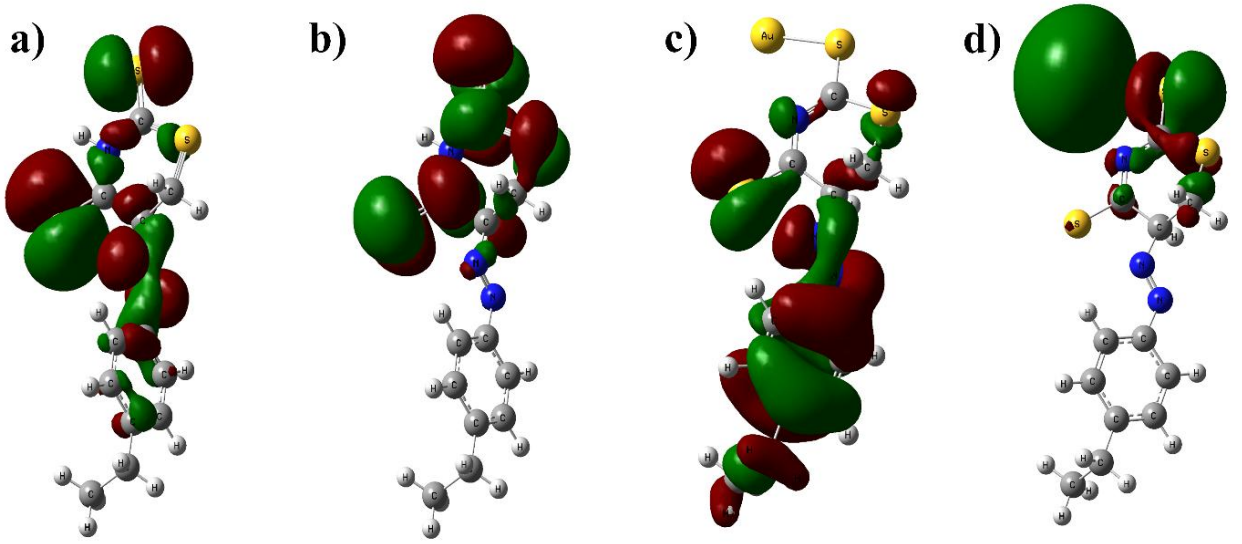

Fig. 7: HOMO (aand c) and LUMO (b and d) orbitals of PSTDT and PSTDT-Au, respectively.

\section{CONCLUSION:-}

The low-content gold determination in samples of copper industry was clearly examined using CT-FAAS, FT-IR and theoretical calculations. The optimum conditions of the sorption capacity of sorbent, $\left[\mathrm{H}^{+}\right]$, temperature and time dependence of PSTDT polymer for gold adsorption were $<45 \mathrm{mg} / \mathrm{g}, 1 \mathrm{~N}, 20{ }^{\circ} \mathrm{C}$ and $15 \mathrm{~min}$, respectively. The analysis efficiency of gold determination was increased after treatment of PSTDT polymer. The chemical interactions and moleculer structure of PSTDT polymer with gold were successfully determined using by FT-IR and theoretical calculations.

\section{ACKNOWLEDGMENT:-}

One of the authors thanks (N. J) for part of calculations to High Level Research Foundation of National University of Mongolia, \#26 (2015-2016). This research was supported by The Asian Research Center in Mongolia and the 
Korean Foundation for Advanced Studies within the framework of the Project \#12 (2016-2017). The authors are grateful to the National University of Mongolia and Yokohama National University for their help under the Research Agreement between them for the calculations.

\section{REFERENCES:-}

1. Olmedo P.A., Hernández A.F., Barbier F., Ayouni L., Gi F.l, (2013): Determination of toxic element (mercury, cadmium, lead, tin and arsenic) in fish and shell fish samples. Risk assessment for the consumers., 59: 63-72.

2. Hoffman E.L., Clark J.R.,Yeager J.R., (1998): Gold analysis-fire assaying and alternative methods. Explor. Mining Geol., 7: 155-160.

3. Hylander LD., Plath D., Miranda C.R., Lücke S., Öhlander J., Rivera A. T. F., (2007): Comparison of different gold recovery methods with regard to pollution control and efficiency. Clean.., 35: 52-61.

4. Pozhidaev Y., Vlasova N., Vasilyeva I., Voronkov M., (2013): Determination of noble metals in rocks and ores using adsorbent PSTM-3T. Adv. Sci. Let., 19: 615- 618.

5. Narantsogt N., Burmaa G., Perlee-Oidov A., Shurkhuu N., Javkhlantugs N., (2014): Molecular modeling of acidic treated PSTM-3T polymer for removal of heavy metal ions by experimental and computational studies. Int. J. Poly. Sci., 2014: 1-6.

6. Basargin N. N., Rozovsky U.G., V. A. Volchenkova U.G., Basargin U. F., (1995): Analysisof gold in natural minerals to enrich by using polystyrene-azo tiazanditionom-2.4., Indust. Lab, 7: 5-7. /In Russian/

7. Becke A.D., (1993): Density-functional thermochemistry. III. The role of exact exchange. J. Chem. Phys. 98: 5648-5652.

8. Becke A.D, (1988): Density-functional exchange-energy approximation with correct asymptotic behavior. Phys. Rev. 38: 3098-3100.

9. Lee C., Yang W., Parr R. G.,( 1988): Development of the colle-salvetti correlation-energy formula in to a functional of the electron density. Phys. Rev. B, 37: 785-789.

10. Hehre W.J., Radom L., Schleyer P. R., Pople J.A., (1987): Ab initio molecular orbital theory. John Wiley \& Sons: New York..

11. Barone V., Bloino J., Biczysko M., (2009): Vibrationally-resolved electronic spectra in GAUSSIAN 09. GAUSSIAN 09 Revision. A.02: 1-20.

12. Frish A., DenningtonII R.D., Keith T.A., Millam J., Nielsen A. B., Holder A.J., Hiscoks J., (2007): Gauss View Version 4.1. Gaussian Inc: Wallingford CT.

13. Coates J., (2004): Encyclopedia of Analytical Chemistry. John Wiley \& Sons.Chichester: UK.

14. Pousti M., Abbaszadeh M., Iashkenari M.S., (2013): A combined experimental and theoretical studies on molecular structure and vibrational spectra of polyaniline and polyaniline/silver nanocomposite. Synthetic Metals. 183: 63-68. 